
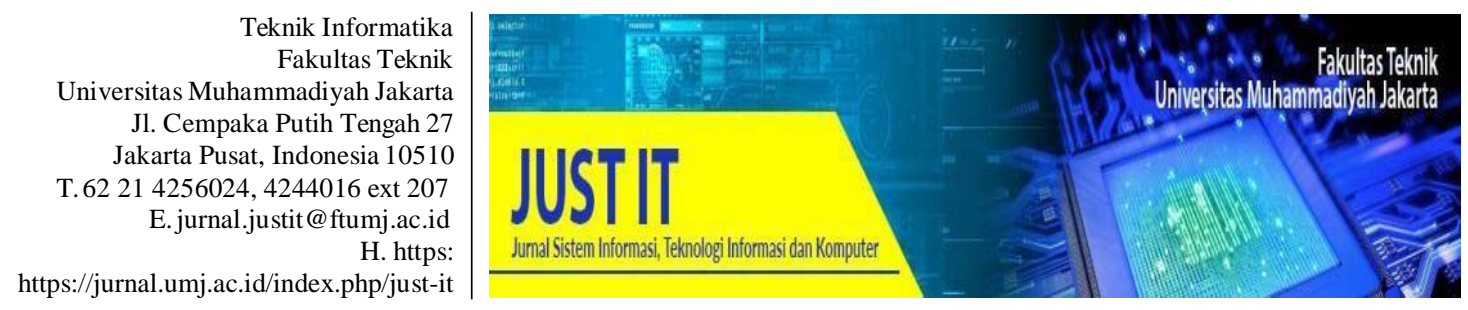

\title{
APLIKASI MONITORING PROGRES PEKERJAAN PROYEK DI BIDANG BINA MARGA DINAS PUPR KABUPATEN PROBOLINGGO BERBASIS WEB
}

\author{
Fathorazi Nur Fajri, Hasbul Bahar, Moh. Budi Utomo Setiawan \\ Teknik Informatika Fakultas Teknik Universitas Nurul Jadid \\ mohbudiutomos@gmail.com
}

\begin{abstract}
Abstrak
Bina marga memiliki tugas pokok dan fungsi salah satunya dalam hal pelaporan pekerjaan proyek, dimana proyek yang ada dalam bina marga di awasi oleh konsultan pengawas lapangan yang akan melaporkan hasil pengawasannya kepada pimpinan yang ada di Bidang Bina Marga. Selama ini untuk melaporkan hasil pekerjaan proyek konsultan pengawas yang ada dilapangan melaporkan hasil pengawasannya dengan megirim pesan via Whatsapp, dan juga staf yang ada di Bina Marga kesulitan dalam merekapitulkasi hasil laporan dari konsultan pengawas dan Pimpinan Bina Marga tidak bisa memantau perkembangan secara harian karena data yang diberikan bersifat mingguan. dan tidak mengetahui secara cepat permasalahan-permasalahan yang terjadi dalam pelaksanaan proyek sehingga terkadang penyelesaiannya terlambat. Aplikasi untuk monitoring progres pekerjaan proyek yang dibangun dengan berbasis web menggunakan PHP dan MySQL. Tujuan dari penelitian yang dilakukan yaitu untuk menghasilkan aplikasi untuk melakukan monitoring progres pekerjaan proyek berbasis web. Manfaat yang diharapkan dari adanya aplikasi monitoring pekerjaan proyek secara online adalah memudahkan proses monitoring pekerjaan proyek yang dapat dilakukan secara online. Dari Penelitian ini dihasilkan aplikasi monitoring progres pekerjaan proyek yang memudahkan konsultan pengawas, staf dan pimpinan dalam memantau progres pekerjaan yang akan dibandingkan dengan progres rencana sehingga dapat mengambil keputusan dalam melakukan perbaikan kedepannya.
\end{abstract}

Kata Kunci: progres, proyek, monitoring, web

\begin{abstract}
Bina marga has one of the main duties and functions in terms of base work, in which projects in bina marga are supervised by field supervisor consultants who will report the results of their supervision to leaders in the Bina Marga Sector. During this time to report the results of work to the supervisory consultant who is in the field reporting the results of supervision by sending messages via Whatsapp, and also staff in Bina Marga have difficulty in recapitulating the results of reports from supervisory consultants and the Director of Bina Marga can not exchange given weekly. and can not solve the problems that occur in the implementation of the project so it was issued resolved later. Application to monitor the progress of project work that is built with webbased using PHP and MySQL. The purpose of the research carried out is to produce an application to monitor the progress of web-based project work. The expected benefit of an online job monitoring application is that it facilitates the process of monitoring project work that can be done online. From this research, the application of monitoring the progress of project work is produced, which makes it easier for supervisory consultants, staff and leaders in the progress of work that will be compared with the progress of the work plan to make decisions in making improvements in the future. .
\end{abstract}

Keywords: progress, project, monitoring, web 


\section{PENDAHULUAN}

Monitoring adalah proses pengumpulan dan analisis informasi berdasarkan indikator yang ditetapkan secara sistematis dan kontinu tentang kegiatan program sehingga dapat dilakukan tindakan koreksi untuk penyempurnaan program kegiatan itu selanjutnya. pemantauan yang dapat dijelaskan sebagai kesadaran (awareness) tentang apa yang ingin diketahui, pemantauan berkadar tingkat tinggi dilakukan agar dapat membuat pengukuran melalui waktu yang menunjukkan pergerakan ke arah tujuan atau menjauh dari itu (Monalisa, 2015)

Definisi proyek dapat diartikan gabungan dari sumber-sumber daya seperti manusia, material, peralatan dan modal/biaya yang dihimpun dalam suatu wadah organisasi sementara unruk mencapai sasaran dan tujuan. Proyek adalah usaha sementara yang dilakukan untuk membuat produk atau jasa unik, sementara berarti bahwa setiap proyek memiliki akhir yang pasti. Unik berarti bahwa produk atau jasa memliki perbedaan dalam beberapa hal yang khusus dibandingkan dengan produk atau jasa yang sejenis. Proyek harus diselesaikan dalam jangka waktu terbatas sesuai dengan waktu kesepakatan (Nugroho, 2012)

Pada penelitian yang dilakukan terhadap progres pengerjaan proyek bidang bina marga bertujuan untuk menghasilkan aplikasi untuk melakukan monitoring progres pekerjaan proyek berbasis web dan tersedia aplikasi pelaporan progres pekerjaan proyek yang terintegrasi sehingga memudahkan instansi dalam memonitoring proyek secara online.

Manfaat yang diharapkan dari adanya aplikasi monitoring progres proyek secara online adalah data-data yang tersimpan selama pelaksanaan proyek akan melengkapi database Aplikasi Monitoring Progres Pekerjaan Proyek sebelumnya dan sangat berguna sebagai acuan perencanaan, perbaikan dan pelaksanaan pekerjaan untuk proyek berikutnya.

\section{METODE PENELITIAN}

Pengumpulan data primer dan sekunder dilakukan untuk memperoleh data-data yang diperlukan dalam penelitian. Data primer diperoleh dengan melakukan wawancara dan survei untuk mendapatkan informasi mengenai jadwal kegiatan, persediaan material, dan proses pelaporan pekerjaan proyek. Data sekunder yang dikumpulkan meliputi data dari hasil studi literature, studi pustaka, penelitian terdahulu, aplikasi tentang web serta perangkat lunak yang digunakan dalam penelitian ini seperti PHP dan MySQL (Juliana, Wibawanti, \& Haikal, 2018)

Dalam penelitian yang dilakukan untuk setelah mengumpulkan data-data yang diperlukan selanjutanya adalah tahap desain sistem yang akan di lakukan dalam proses perancangan, pembuatan lalu tahap implementasi sitem. Pada penelitian ini menggunakan metode waterfall. Seperti gambar dibawah ini :

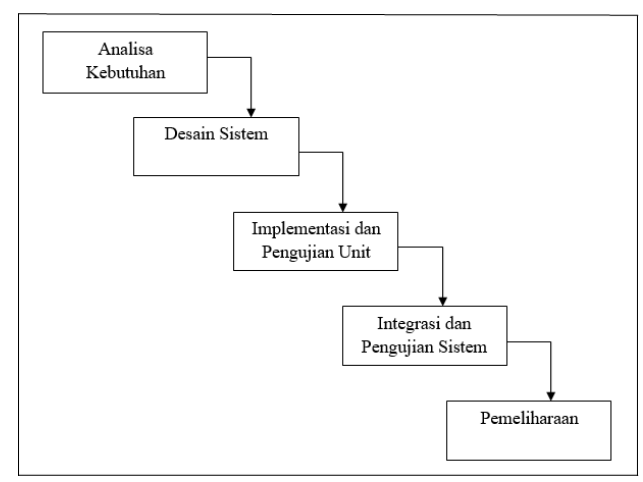

Gambar. 1. Metode waterfall. 
Analisa kebutuhan merupakan proses pengumpulan kebutuhan yang dilakukan secara intensif untuk menspesifikasikan kebutuhan perangkat lunak yang dikembangkan. Analisa kebutuhan berguna untuk mengetahui dan memahami kebutuhan perangkat lunak yang nantinya digunakan oleh pengguna. Proses analisa kebutuhan dilakukan dengan melakukan observasi mengenai permasalahan di Bidang Bina Marga dan menentukan objek apa saja yang dijadikan inti dari perangkat lunak yang akan dibuat.

Desain merupakan proses multi langkah yang fokus pada desain pembuatan perangkat lunak termasuk struktur data, arsitektur perangkat lunak, representasi antar muka dan prosedur pengkodean. Tahap ini menstranlasi kebutuhan perangkat lunak dari tahap analisa kebutuhan ke representasi desain agar dapat diimplementasikan menjadi program dalam tahapan selanjutnya.

Untuk dapat dimengerti oleh mesin, dalam hal ini adalah komputer, maka desain yang sudah dibuat kemudian diimplementasi dalam bentuk yang dapat dimengerti oleh mesin, yaitu ke dalam bahasa pemograman melalui proses pengkodean (coding).

Dalam tahapan ini, setiap unit program akan di integrasikan satu sama lain dan diuji sebagai satu sistem yang utuh untuk memastikan sistem sudah memenuhi persyaratan yang ada dan bebas dari error atau kesalahan. Setelah itu sistem akan dipublikasi untuk dapat digunakan oleh user.

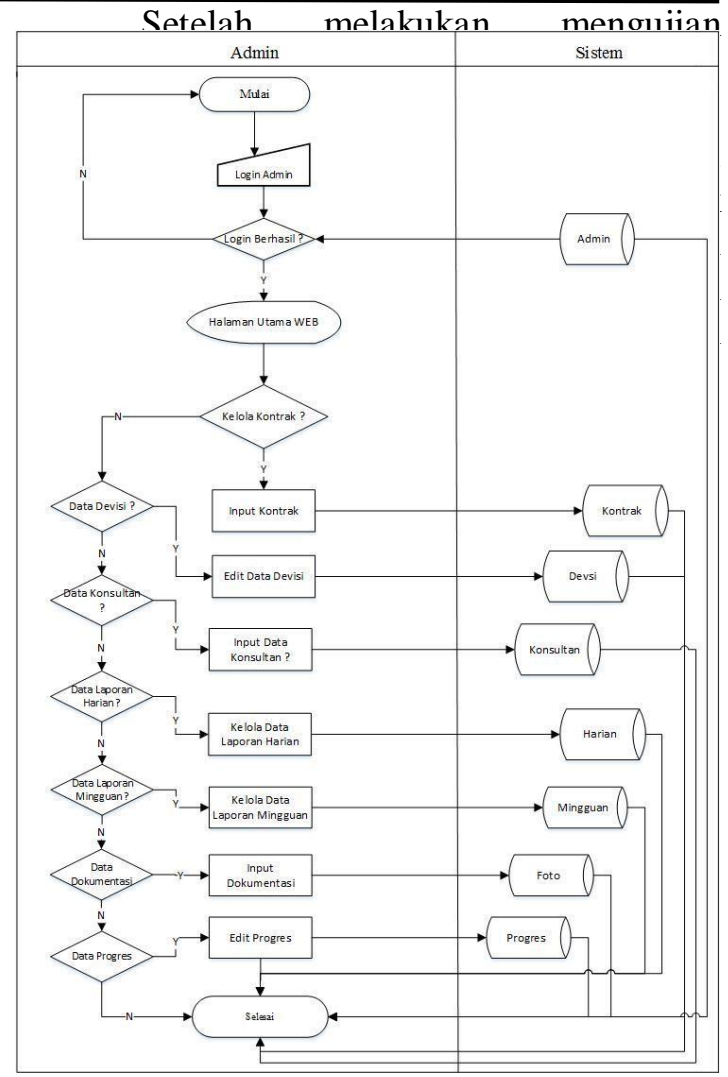

Gambar. 2. Proses Administrator.

Data Flow Diagram level 1 lebih terperinci karena menambah proses hubungan yang terjadi pada sistem sehingga hubungan antara entitas dan proses akan di membentuk sistem secara utuh. Berikut gambaran data flow diagram level 1 dapat dilihat pada Gambar 3. sebagai berikut: 


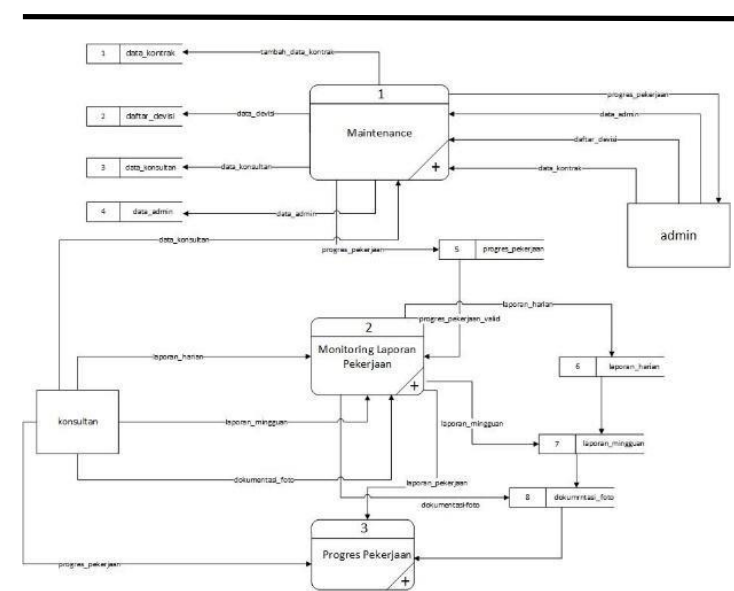

Gambar. 3. Data Flow Diagram Level 1.

Setelah diperoleh gambaran mengenai data flow diagram yang akan diterapkan pada sistem yang akan dibangun, maka langkah selanjutnya adalah menentukan pola hubungan antar entitas yang membentuk sistem monitoring progres pekerjaan proyek dalam bentuk ER Diagram.

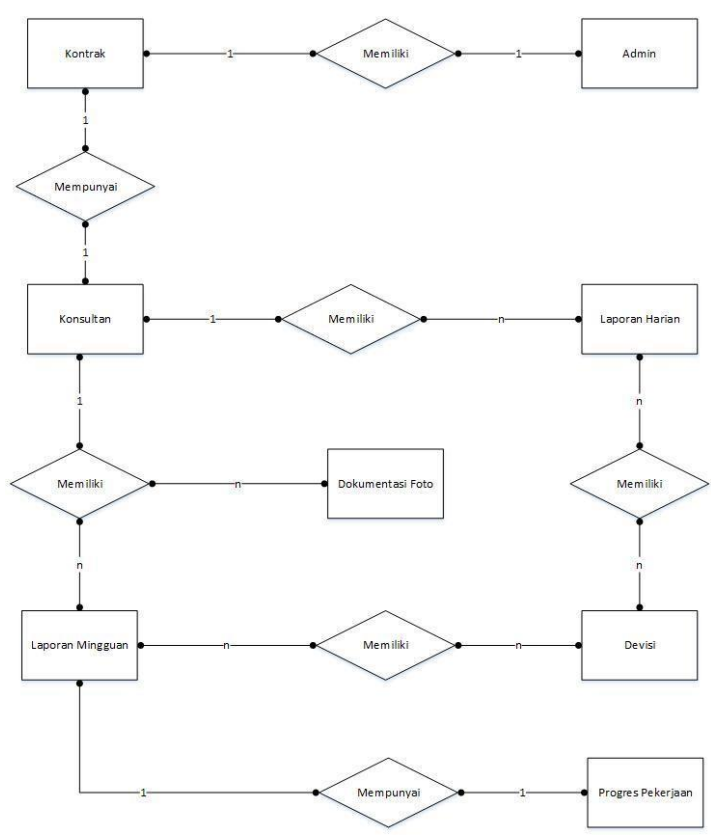

Gambar. 4. Entity Relationship Diagram.

Halaman login setiap kali seseorang akan menggunakan aplikasi ini, terlebih dahulu melakukan login dengan cara mengisi usernama dan password.

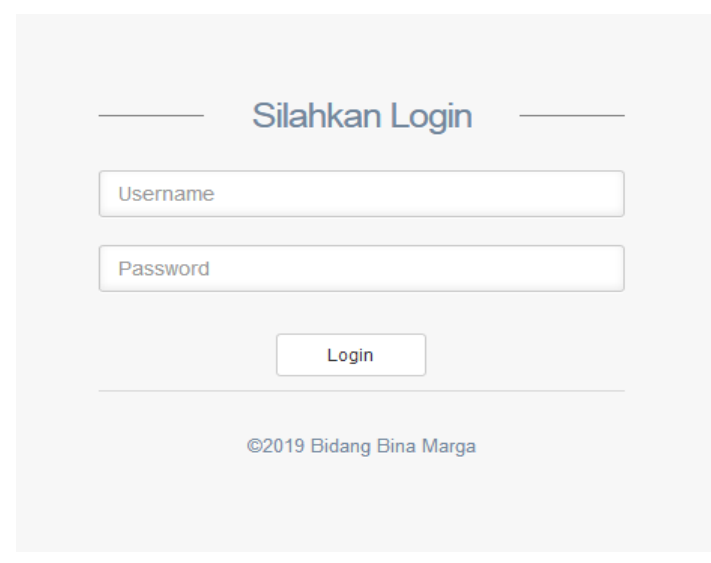

Gambar. 5. Halaman login.

Setelah melakukan login dengan mengisi username dan password dengan benar maka aplikasi akan meumculkan halaman utama.
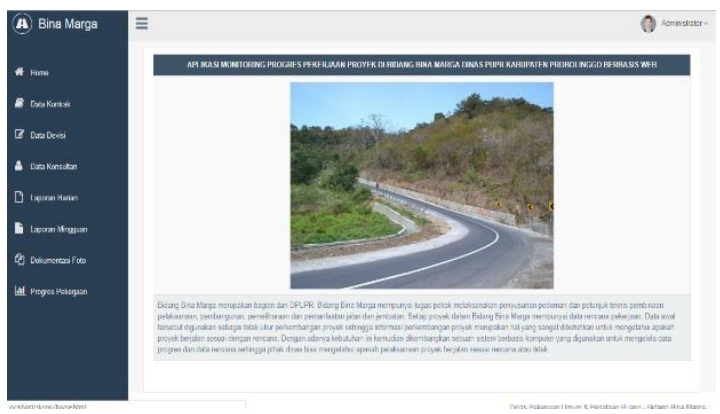

Gambar. 6. Halaman utama.

Output dokumentasi foto kontrak berupa excel seperti gambar berikut:

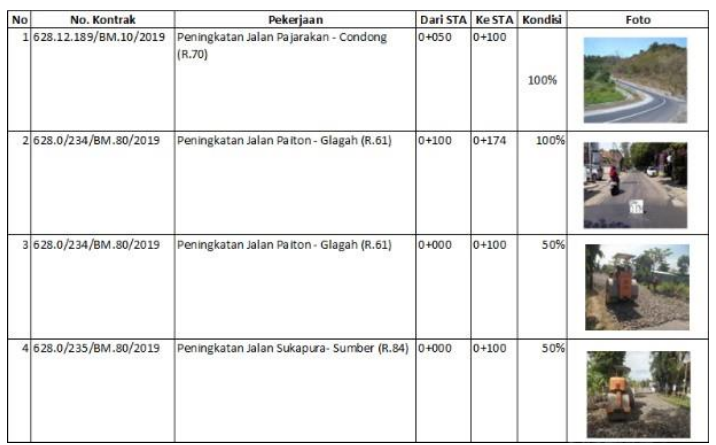

Gambar. 7. Output Dokumentasi Foto.

Grafik progres pekerjaan berupa grafik garis seperti gambar berikut: 


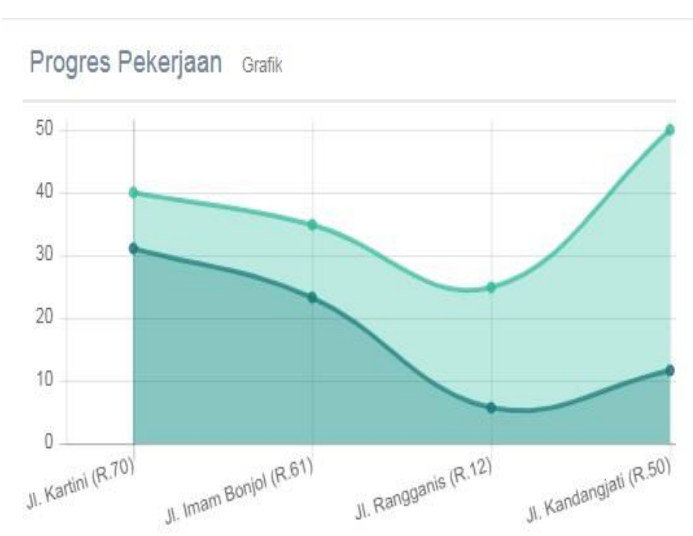

Gambar. 8. Grafik Progres Pekerjaan.

Tabel progres pekerjaan seperti gambar berikut:

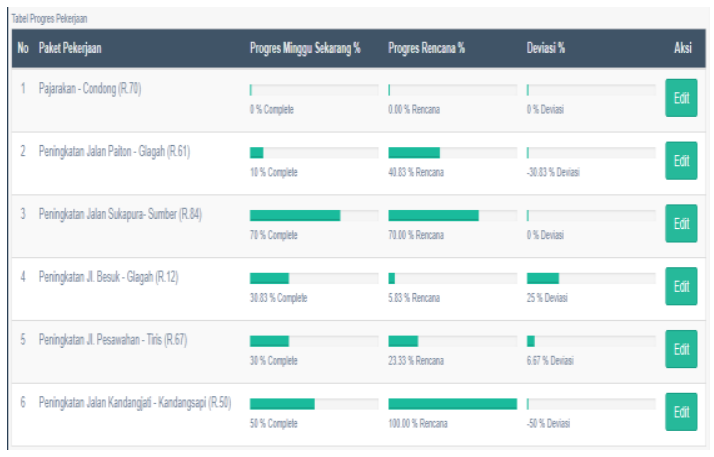

Gambar. 9. Tabel Progres Pekerjaan.

Black Box Testing berfokus pada spesifikasi fungsional dari perangkat lunak. Tester dapat mendefinisikan kumpulan kondisi input dan melakukan pengetesan pada spesifikasi fungsional program.

1. Perkembangan Proyek itu apa ?

2. Bagaimana Proses Monitoring yang ada dilapangan?

3. Apa saja macam-macam laporan yang diberikan konsultan?

4. Apa saja dan bagaimana konsultan dalam melakukan pelaporan?

5. Bagaimana cara membuat rekapitulasi laporan?

6. Kapan laporan disetor ke instansi?

\section{KESIMPULAN}

Telah dihasilkan aplikasi monitoring progres pekerjaan proyek di bidang bina marga berbasis web sehingga mempermudah dalam pengolahan data dan memantau perkembangan proyek yang ada dilapangan. Aplikasi ini mampu mempermudah kinerja bidang bina marga terbukti dengan hasil wawancara dan pengujian blackbox yang menunjukan bahwa aplikasi yang telah di bangun dapat bekerja sesuai keinginan user.

\section{DAFTAR PUSTAKA}

Juliana, J., Wibawanti, Y., \& Haikal, M. (2018). Monitoring Kemajuan Pengerjaan Proyek Belt Conveyor Plant 14 Hambalang Berbasis Web. Simetris: Jurnal Teknik Mesin, Elektro Dan Ilmu Komputer, 9(1), 29-34. https://doi.org/10.24176/simet.v9i1.164 6

Monalisa, S. (2015). RANCANG BANGUN SISTEM INFORMASI MONITORING PERKEMBANGAN PROYEK BERBASIS WEB (STUDI KASUS: PT. INTI PRATAMA SEMESTA). Jurnal

Rekayasa Dan Manajemen Sistem Informasi, 1(1), 49-54.

MUDJAHIDIN, M., \& DITA PAHANG PUTRA, N. (2017). RANCANG BANGUN SISTEM INFORMASI MONITORING PERKEMBANGAN PROYEK BERBASIS WEB. Jurnal Teknik Industri. https://doi.org/10.22219/jtiumm.vol11.n o1.75-83

Nugroho, Y. P. (2012). Pengembangan sistem informasi manajemen proyek berbasis website (Studi Kasus: Pelaksanaan Proyek Konstruksi di Kampus UNDIP Tembalang).

Rahman, R. A. (2016). Rancang Bangun Sistem Informasi Monitoring Pekerjaan Umum dengan Pendekatan Konsep Nilai Hasil. In Jurnal Transistor Elektro dan Informatika (TRANSISTOR EI) (Vol. 1).

Sugoro, P., Hasyim, M. H., Saifoe, D., \& Unas, E. (n.d.). Monitoring Pada Pembangunan Proyek Terminal Penumpang Kabupaten Barru Sulawesi Selatan Dengan Metode Konsep Nilai Hasil Dikonversikan Terhadap Kurva s. 